\title{
Ritz Variational Method for the Flexural Analysis of Rectangular Kirchhoff Plate on Winkler Foundation
}

\author{
Ike C. C.*
}

Enugu State University of Science and Technology, P.M.B. 01660, Enugu, Nigeria

\author{
Article info: \\ Paper received: \\ The final version of the paper received: \\ Paper accepted online:
}

May 19, 2018

December 14, 2018

December 18, 2018
*Corresponding Author's Address: charles.ike@esut.edu.ng

\begin{abstract}
In this study, the Ritz variational method has been applied to solve the bending problem of rectangular Kirchhoff plate resting on Winkler foundation for the case of simply supported edges and transverse distributed load. The problem was presented in variational form using energy principles to obtain the total potential energy functional. Ritz technique was then used to find the generalised displacement parameters which minimized the total potential energy functional; where basis functions were choose to apriori satisfy the boundary conditions. Analytical solutions were obtained which were found to be identical with Navier's series solutions for the general case of arbitrary distributed transverse load, as well as the specific cases of point loads, sinusoidal load, uniform and linearly distributed loads.
\end{abstract}

Keywords: Ritz variational method, Kirchhoff plate, Winkler foundation, total potential energy functional, generalised displacement parameters, displacement basis functions.

\section{Introduction}

Problems of the flexure of plates resting on elastic foundations are fundamental in geotechnical and structural engineering and analysis. They are encountered in the analysis and design of foundations such as column footings, combined footings and raft foundations. They are also encountered in problems of structural analysis that are mathematical analogues of the plate on Winkler foundation problem. Many theories exist for the analysis of the flexural behaviour of plates. They include: Lagrange plate theory, Germain theory, Kirchhoff theory, Von Karman theory, Reissner [1, 2] theory, Mindlin [3], Shimpi [4] theory, Reddy [5] theory, and other variants of Refined plate theory and shear deformation plate theories. Kirchhoff plate theory also called the classical thin plate theory is adopted in this paper. The fundamental hypothesis of the Kirchhoff plate theory includes:

1) straight lines normal to the plate's middle surface remain straight after bending deformation;

2) straight lines normal to the plate middle surface before deformation remain normal to the middle surface after bending deformation;

3 ) the thickness of the plate does not change during flexural deformation.
The Kirchhoff plate theory is a two dimensional approximation of the mathematical theory of elasticity applied to plates to determine the stress and deformation fields in thin plates subject to forces and moments under different restraint conditions. It is an extension of the Euler-Bernoulli beam theory, and assumes that a middle plane surface, neutral during deformation can be used to represent a three dimensional plate in two dimensional form (Mama et al, [6]). The obvious merits of Kirchhoff plate theory include:

1) the problem is reduced to two dimensional one;

2) the uncoupling of bending and stretching behaviours;

3) the linear nature of the governing partial differential equation;

4) stresses can be calculated from the stressdisplacement relations;

$5)$ it is commonly applied.

The most significant defect is the neglect of transverse shear deformation and its inability to model cases in which shear deformation plays a significant role. The interaction of soil on the foundation structure is represented by the soil reactive pressure distribution (Caselunghe and Erikson, [7]). 
Many models exist for describing the soil interaction on the foundation structure. The elastic foundation models are classified as discrete parameter models, simplified elastic continuum models and elastic continuum models (Rajpurohit et al, [8]; Ghaitani et al, [9]). In discrete parameter models, the elastic foundation is modeled as a set of closely spaced discrete individual springs that may or may not be coupled to one another. In continuum models, the mathematical theory of elasticity is used to find complex analytical expressions that describe the soil reaction. Simple elastic continuum foundation models are models that may be described as simplifications of the theory of elasticity formulation for the soil reaction. Discrete parameter foundation models include: Winkler [10], Pasternak [11], Filonenko-Borodich [12], and Hetenyi [13] foundation models, as well as generalised two- and multiparameter foundation models.

The simplest representation of soil reactive pressure distribution is provided by the classical Winkler foundation model which replaces the subgrade by a mechanical analogy made up of single bed of closely spaced independent vertical springs, without interaction with one another. In the Winkler foundation idealization, the soil reaction at any point on the foundation (plate) is directly proportional to the deformation of the foundation (plate) at that point. Thus, analytically,

$$
p(x, y)=k_{s} w(x, y)
$$

where $p(x, y)$ is the soil reactive pressure distribution at an arbitrary point $(x, y)$ in the plate-soil interface area, $w(x, y)$ is the corresponding vertical deformation and $k_{s}$ is the constant of proportionality, representing contact pressure per unit deformation - commonly referred to as the Winkler coefficient or coefficient of subgrade reaction or simply the subgrade modulus.

Hence in the Winkler model, $k_{s}$ is the only foundation parameter characterizing the elastic response of the soil, Winkler's foundation has the basic demerit of resulting in a vertical deformation of only those springs alone that are located under the loaded region. Thus the Winkler model leads to discontinuity of vertical deformation at the edges of the loaded plate. In addition, the Winkler model implies that a point undergoes vertical deformation that is independent of the vertical deformation of other adjoining points; which is not in line with elasticity findings. These shortcomings have led to the development of other discrete parameter foundation models that account for the effect of shear interaction (Pasternak, [11]). However, the simplificity of the Winkler model and its long term familiarity has ensured its usage till today. The FilonenkoBorodich, and Pasternak foundation models are two parameter discrete parameter foundation models where the soil reaction pressure is given generally by (Pasternak, [11]):

$$
p(x, y)=k_{1} w(x, y)-k_{2} \nabla^{2} w(x, y),
$$

where $k_{1}$ and $k_{2}$ are two discrete parameters of the model, and $\nabla^{2}$ is the Laplacian operator with respect to coordinates $x, y$. In the Kerr [14] model, a shear layer is introduced in the numerator Winkler foundation and the shear layer separates the elastic bed into two beds with two different spring constants, $k_{1}$ for the first layer interfacing the plate and $k_{2}$ for the second layer making contact with a rigid base.

The governing differential equation of the Kerr [14] foundation is given by

$$
\left(1+\frac{k_{2}}{k_{1}}\right) p=\frac{G}{k_{1}} \nabla^{2} p+k_{2} w-G \nabla^{2} w,
$$

where $k_{1}$ is the spring constant of the first layer, $k_{2}$, the spring constant of the second layer and $w(x, y)$ is the deflection of the first layer, $G$ is the shear modulus of the shear layer which separates the first and second layers in a Kerr foundation.

The research [15] expanded the previous work done by Mama et al [6] by considering new particular types of distributed transverse load namely, bisinusoidal distribution and linear distribution over the entire plate domain and using the Fourier sine transform method. In addition, paper [15] considered and solved numerical problems for simply supported Kirchhoff plates resting on Winkler foundations for different values of the dimensionless Winkler parameter; for cases of uniformly distributed transverse load on the plate domain.

Other researchers who have studied the plate on elastic foundation problem are: Althobaiti and Prikazchikov [16]; Zhong, Zhao and Hu [17]; Li, Zhong and Li [18]; Li, Zhong and Tian [19]; Li et al [20]; Zhang, Shi and Wang [21]; Agarana, Gbadeyan and Ajayi [22]; Are, Idowu and Gbadeyin [23]; Agarana and Gbadeyin [24]; Tahuoneh and Yas [25]; and Ye et al [26].

The research aim is to apply the Ritz variational method to obtain solutions for the flexural problem of simply supported Kirchhoff plate resting on Winkler foundation for cases of transversely distributed loads. The specific objectives include:

1) to obtain the Ritz variational statement of the problem of Kirchhoff plate on Winkler foundation for the case of arbitrary distribution of transverse loads;

2) to solve the variational problem using the energy minimization principle to obtain the general solution for the deflection for any distributed load as well as the corresponding internal force resultants;

3) to obtain solutions for deflections and internal forces for particular types of transverse loads namely:

- point load $P_{0}$ applied at a known point $\left(x_{0}, y_{0}\right)$ on the plate domain;

- bisinusoidal distributed load over the entire plate domain;

- uniformly distributed load over the entire plate domain;

- linearly distributed load over the plate domain. 


\section{Research Methodology}

Kirchhoff plate theory was adopted for the plate while Winkler foundation model was used to describe the soil reaction pressure on the plate. Kirchhoff plate theory is based on the following kinematic assumptions:

1) straight lines normal to the middle surface remain straight after deformation;

2) straight lines normal to the middle surface remain normal to the middle surface after deformation;

3 ) the thickness of the plate does not change during flexural deformation.

Using the strain energy density for a generalised three dimensional state of stress, the generalized Hooke's stress-strain law for isotropic elastic plates and the fundamental assumption of thin plate theory, the bending strain energy functional $U_{b}$ for the Kirchhoff plate is obtained by the following formula:

$$
U_{b}=\frac{D}{2} \iint_{R}\left[\left(\nabla^{2} w\right)^{2}+2(1-\mu)\left(w_{x y}^{2}-w_{x x} w_{y y}\right)\right] d x d y
$$

where $R$ is the two dimensional domain of the plate on the $x y$ coordinate plane, $D$ is the plate flexural rigidity given by

$$
D=\frac{E h^{3}}{12\left(1-\mu^{2}\right)}
$$

$h$ is the plate thickness, $w_{x x}$ denotes the second partial derivative of $w(x, y)$ with respect to $x$, while $w_{x y}$ is the mixed partial derivative of $w(x, y)$ with respect to $x$ and $y$ variables.

The potential energy of the distributed transverse load $p(x, y)$ is given by

$$
V=-\iint_{R} p(x, y) w(x, y) d x d y .
$$

The potential energy functional due to the Winkler foundation is given by:

$$
W_{s}=\frac{1}{2} \iint_{R} k(w(x, y))^{2} d x d y,
$$

where $p_{s}(x, y)$ is the soil reactive pressure on the plate. The total potential energy functional $\Pi$ then becomes

$$
\Pi=U_{b}+W_{s}+V ;
$$

The problem of flexure under static transverse loads for Kirchhoff plate on Winkler foundation then reduces to one of finding the value of the deflection $w(x, y)$ that minimizes the total potential energy functional expressed as the abovementioned equation; a problem situated in calculus of variations. Thus, for equilibrium of the Kirchhoff plate on Winkler foundation problem

$$
\delta \Pi=0,
$$

where $\delta \Pi$ denotes the first variation in the total potential energy functional.
Ritz variational method is based on the principle of minimum total potential energy functional for equilibrium. The principle states that the displacement field (function) that corresponds to the minimum total potential energy functional represents a state of equilibrium, provided the displacement function satisfies the given boundary conditions. Thus, the Ritz variational method seeks to obtain the displacement field defined over the plate domain such that the total potential energy functional of the Kirchhoff plate on Winkler foundation carrying known transverse distributed load is minimized. In the Ritz method, the unknown displacement field (function) $w(x, y)$ is sought or defined in terms of a finite or infinite number of basis (shape or coordinate) functions as follows:

$$
w(x, y)=\sum_{m}^{\infty} \sum_{n}^{\infty} w_{m n} X_{m}(x) Y_{n}(y),
$$

where $X_{m}(x)$ and $Y_{n}(y)$ are the basis (coordinate or shape) functions in the $x$ and $y$ coordinate directions respectively, chosen such that they identically satisfy the end condition along the $x$ and $y$ directions respectively; and $w_{m n}$ are the generalised displacement parameters which are sought.

For Kirchhoff plate on Winkler foundation, extremization of the total potential energy functional (8) in terms of the unknown generalised displacement parameters $w_{m n}$

$$
\frac{\partial \Pi}{\partial w_{m n}}=0
$$

allows obtaining the system of algebraic equations:

$$
\sum_{m=1}^{\infty} \sum_{n=1}^{\infty} k_{m n} w_{m n}=\sum_{m=1}^{\infty} \sum_{n=1}^{\infty} F_{m n} .
$$

\section{Results}

\subsection{Arbitrary distributed load $p(x, y)$ over the simply supported Kirchhoff plate}

A rectangular Kirchhoff plate of length $a$ and width $b$ resting on Winkler foundation as shown in Figure 1 was considered.

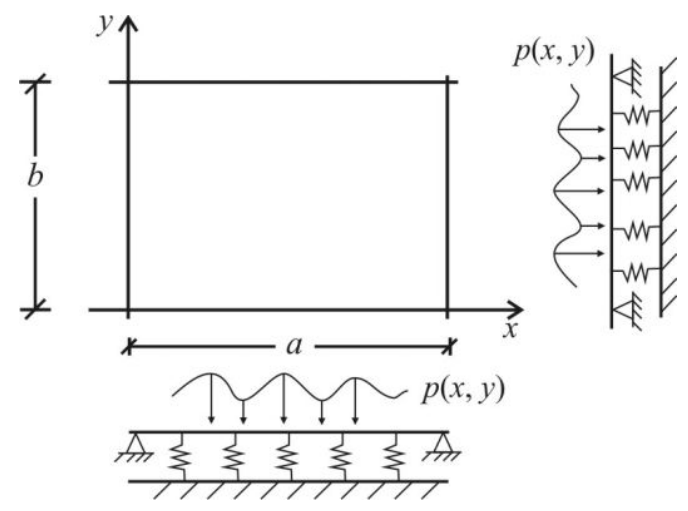

Figure 1 - Kirchhoff plate on Winkler foundation under arbitrary load, $p(x, y)$ 
The geometric and force boundary conditions at the simply supported edges are: $w(0, y)=w(a, y)=0$; $\frac{\partial^{2} w}{\partial x^{2}}(x=0, y)=\frac{\partial^{2} w}{\partial x^{2}}(x=a, y)=0 ; w(x, 0)=w(x, b)=0 ;$
$\frac{\partial^{2} w}{\partial y^{2}}(x, y=0)=\frac{\partial^{2} w}{\partial y^{2}}(x, y=b)=0$.

The displacement basis functions that satisfy the boundary conditions are:

$$
X_{m}(x)=\sin \frac{m \pi x}{a}=\sin \alpha_{m} x ; Y_{n}(x)=\sin \frac{n \pi y}{b}=\sin \beta_{n} y,
$$

where $\alpha_{m}=\frac{m \pi}{a} ; \beta_{n}=\frac{n \pi}{b}$.

For simply supported plates, the Gaussian curvature given by $\left(w_{x y}^{2}-w_{x x} w_{y y}\right)$ contributes nothing to the total potential energy since its integral vanishes and $\Pi$ simplifies to:

$$
\Pi=\frac{D}{2} \iint_{R}\left(\nabla^{2} w\right)^{2} d x d y+\frac{1}{2} \iint_{R} k w^{2}-\iint_{R} p w d x d y .
$$

Let the arbitrary distributed transverse load be represented using Fourier sine series as

$$
p(x, y)=\sum_{m=1}^{\infty} \sum_{n=1}^{\infty} p_{m n} \sin \frac{m \pi x}{a} \sin \frac{n \pi y}{b} .
$$

where $p_{m n}$ are the Fourier coefficients of the distributed load, then

$$
\begin{aligned}
& \Pi=\frac{D}{2} \sum_{m}^{\infty} \sum_{n}^{\infty}\left(\left(\frac{m \pi}{a}\right)^{2}+\left(\frac{n \pi}{b}\right)^{2}\right)^{2} w_{m n}^{2} I_{1}+ \\
& +\frac{1}{2} k \sum_{m}^{\infty} \sum_{n}^{\infty} w_{m n}^{2} I_{1}-p_{m n} w_{m n} I_{1},
\end{aligned}
$$

where

$$
I_{1}=\int_{0}^{a} \int_{0}^{b} \sin ^{2} \frac{m \pi x}{a} \sin ^{2} \frac{n \pi y}{b} d x d y .
$$

Extremizing $\Pi$ with respect to the generalised coordinates after simplifying allows obtaining

$$
w_{m n}=\frac{p_{m n} / D}{\left(\left(\frac{m \pi}{a}\right)^{2}+\left(\frac{n \pi}{b}\right)^{2}\right)^{2}+\left(\frac{k}{D}\right)} .
$$

Using the dependence

$$
p_{m n}=\frac{4}{a b} \int_{0}^{a} \int_{0}^{b} p(x, y) \sin \frac{m \pi x}{a} \sin \frac{n \pi y}{b} d x d y,
$$

it can be obtained:

$$
w(x, y)=\sum_{m}^{\infty} \sum_{n}^{\infty} \frac{p_{m n} \sin \frac{m \pi x}{a} \sin \frac{n \pi y}{b}}{D\left[\left(\left(\frac{m \pi}{a}\right)^{2}+\left(\frac{n \pi}{b}\right)^{2}\right)^{2}+\frac{k}{D}\right]} .
$$

In this case, the bending and twisting moments are

$$
\begin{aligned}
& M_{x x}=\sum_{m}^{\infty} \sum_{n}^{\infty} \frac{\left(\left(\frac{m \pi}{a}\right)^{2}+\mu\left(\frac{n \pi}{b}\right)^{2}\right) p_{m n} \sin \frac{m \pi x}{a} \sin \frac{n \pi y}{b}}{\left[\left(\left(\frac{m \pi}{a}\right)^{2}+\left(\frac{n \pi}{b}\right)^{2}\right)^{2}+\frac{k}{D}\right]} \\
& M_{y y}=\sum_{m}^{\infty} \sum_{n}^{\infty} \frac{\left(\left(\frac{n \pi}{b}\right)^{2}+\mu\left(\frac{m \pi}{a}\right)^{2}\right) p_{m n} \sin \frac{m \pi x}{a} \sin \frac{n \pi y}{b}}{\left[\left(\left(\frac{m \pi}{a}\right)^{2}+\left(\frac{n \pi}{b}\right)^{2}\right)^{2}+\frac{k}{D}\right]} ; \\
& M_{x y}=-(1-\mu) \sum_{m}^{\infty} \sum_{n}^{\infty} \frac{p_{m n}\left(\frac{m \pi}{a} \frac{n \pi}{b}\right) \cos \frac{m \pi x}{a} \cos \frac{n \pi y}{b}}{\left(\left(\frac{m \pi}{a}\right)^{2}+\left(\frac{n \pi}{b}\right)^{2}\right)^{2}+\frac{k}{D}} .
\end{aligned}
$$

\subsection{Ritz variational solutions for point load $P_{0}$ at $\left(x_{0}, y_{0}\right)$}

For the case of point load $P_{0}$ applied at the arbitrary point $x_{0}, y_{0}$, within the plate domain, the Fourier series coefficient $p_{m n}$ is

$$
p_{m n}=\frac{4 P_{0}}{a b} \sin \frac{m \pi x_{0}}{a} \sin \frac{n \pi y_{0}}{b} .
$$

Then, the solutions for transverse deflections and bending moments become:

$$
\begin{aligned}
& w(x, y)=\frac{4 P_{0}}{a b D} \sum_{m}^{\infty} \sum_{n}^{\infty} \frac{\sin \frac{m \pi x_{0}}{a} \sin \frac{n \pi y_{0}}{b} \sin \frac{m \pi x}{a} \sin \frac{n \pi y}{b}}{\left(\left(\frac{m \pi}{a}\right)^{2}+\left(\frac{n \pi}{b}\right)^{2}\right)^{2}+\frac{k}{D}} \\
& M_{x x}=\frac{4 P_{0}}{a b} \sum_{m}^{\infty} \sum_{n}^{\infty} \frac{\left(\left(\frac{m \pi}{a}\right)^{2}+\mu\left(\frac{n \pi}{b}\right)^{2}\right) \sin \frac{m \pi x_{0}}{a} \sin \frac{m \pi x}{a} \sin \frac{n \pi y_{0}}{b} \sin \frac{n \pi y}{b}}{\left(\left(\frac{m \pi}{a}\right)^{2}+\left(\frac{n \pi}{b}\right)^{2}\right)^{2}+\frac{k}{D}} \\
& M_{y y}=\frac{4 P_{0}}{a b} \sum_{m}^{\infty} \sum_{n}^{\infty} \frac{\left(\left(\frac{n \pi}{b}\right)^{2}+\mu\left(\frac{m \pi}{a}\right)^{2}\right) \sin \frac{m \pi x_{0}}{a} \sin \frac{m \pi x}{a} \sin \frac{n \pi y_{0}}{b} \sin \frac{n \pi y}{b}}{\left(\left(\frac{m \pi}{a}\right)^{2}+\left(\frac{n \pi}{b}\right)^{2}\right)^{2}+\frac{k}{D}}
\end{aligned}
$$

where $m, n=\{1,3,5, \ldots\}$.

When the point load is applied at the center of the plate $\left(x_{0}=a / 2, y_{0}=b / 2\right)$, the maximum deflection and bending moments would occur at the plate center and are found as:

$$
\begin{aligned}
& w(a / 2, b / 2)=\frac{4 P_{0}}{a b D} \sum_{m}^{\infty} \sum_{n}^{\infty} \frac{\sin ^{2} \frac{m \pi}{2} \sin ^{2} \frac{n \pi}{2}}{\left(\left(\frac{m \pi}{a}\right)^{2}+\left(\frac{n \pi}{b}\right)^{2}\right)^{2}+\frac{k}{D}} \\
& M_{x x}(a / 2, b / 2)=\frac{4 P_{0}}{a b} \sum_{m}^{\infty} \sum_{n}^{\infty} \frac{\left(\left(\frac{m \pi}{a}\right)^{2}+\mu\left(\frac{n \pi}{b}\right)^{2}\right) \sin ^{2} \frac{m \pi}{2} \sin ^{2} \frac{n \pi}{2}}{\left(\left(\frac{m \pi}{a}\right)^{2}+\left(\frac{n \pi}{b}\right)^{2}\right)^{2}+\frac{k}{D}} \\
& M_{y y}(a / 2, b / 2)=\frac{4 P_{0}}{a b} \sum_{m}^{\infty} \sum_{n}^{\infty} \frac{\left(\left(\frac{n \pi}{b}\right)^{2}+\mu\left(\frac{m \pi}{a}\right)^{2}\right) \sin ^{2} \frac{m \pi}{2} \sin ^{2} \frac{n \pi}{2}}{\left(\left(\frac{m \pi}{a}\right)^{2}+\left(\frac{n \pi}{b}\right)^{2}\right)^{2}+\frac{k}{D}}
\end{aligned}
$$


For square plates on Winkler foundation where the point load $P_{0}$ acts at the center $(a=b)$, and the maximum deflection and bending moments occur at the center, and are given by:

$$
\begin{aligned}
& w(a / 2, b / 2)=\frac{4 P_{0} a^{2}}{D} \sum_{m}^{\infty} \sum_{n}^{\infty} \frac{\sin ^{2} \frac{m \pi}{2} \sin ^{2} \frac{n \pi}{2}}{\left(\pi^{4}\left(m^{2}+n^{2}\right)^{2}+\frac{k a^{4}}{D}\right)} ; \\
& M_{x x}(a / 2, b / 2)=4 P_{0} \sum_{m}^{\infty} \sum_{n}^{\infty} \frac{\pi^{2}\left(m^{2}+\mu n^{2}\right) \sin ^{2} \frac{m \pi}{2} \sin ^{2} \frac{n \pi}{2}}{\pi^{4}\left(m^{2}+n^{2}\right)^{2}+\frac{k a^{4}}{D}} .
\end{aligned}
$$

Additionally, $M_{y y}(a / 2, b / 2)=M_{x x}(a / 2, b / 2)$.

\subsection{Ritz variational solutions for transverse sinusoidal load}

In the case of transverse sinusoidal load $p(x, y)=p_{0} \sin \frac{\pi x}{a} \sin \frac{\pi y}{b}$, the Fourier sine series coefficient for the sinusoidal load $p_{m n}=p_{0} \quad m=1, \quad n=1$ and $p_{m n}=0 \quad m \neq 1, \quad n \neq 1$. Then by substitution into the Ritz variational solutions for arbitrary distribution of transverse load, the solutions for sinusoidal loads become:

$$
\begin{gathered}
w(x, y)=\frac{p_{0} \sin \frac{\pi x}{a} \sin \frac{n y}{b}}{D\left[\left(\left(\frac{\pi}{a}\right)^{2}+\left(\frac{\pi}{b}\right)^{2}\right)^{2}+\frac{k}{D}\right]} ; \\
M_{x x}=\frac{\left(\left(\frac{\pi}{a}\right)^{2}+\mu\left(\frac{\pi}{b}\right)^{2}\right) p_{0} \sin \frac{\pi x}{a} \sin \frac{n y}{b}}{\left(\left(\frac{\pi}{a}\right)^{2}+\left(\frac{\pi}{b}\right)^{2}\right)^{2}+\frac{k}{D}} ; \\
M_{y y}=\frac{\left(\left(\frac{\pi}{b}\right)^{2}+\mu\left(\frac{\pi}{a}\right)^{2}\right) p_{0} \sin \frac{\pi x}{a} \sin \frac{n y}{b}}{\left(\left(\frac{\pi}{a}\right)^{2}+\left(\frac{\pi}{b}\right)^{2}\right)^{2}+\frac{k}{D}} .
\end{gathered}
$$

The maximum values of deflection and bending moments occur at the plate center, and are given by:

$$
\begin{gathered}
w(a / 2, b / 2)=\frac{p_{0} \sin ^{2}(\pi / 2)}{D\left[\left(\left(\frac{\pi}{a}\right)^{2}+\left(\frac{\pi}{b}\right)\right)^{2}+\frac{k}{D}\right]} ; \\
M_{x x}(a / 2, b / 2)=\frac{\left((\pi / a)^{2}+\mu(\pi / b)^{2}\right) p_{0} \sin ^{2}(\pi / 2)}{\left(\left(\frac{\pi}{a}\right)^{2}+\left(\frac{\pi}{b}\right)^{2}\right)^{2}+\frac{k}{D}} ; \\
M_{y y}(a / 2, b / 2)=\frac{\left((\pi / b)^{2}+\mu(\pi / a)^{2}\right) p_{0} \sin ^{2}(\pi / 2)}{\left(\left(\frac{\pi}{a}\right)^{2}+\left(\frac{\pi}{b}\right)^{2}\right)^{2}+\frac{k}{D}} .
\end{gathered}
$$

For square plates $(a=b)$ it can be obtained:

$$
\begin{gathered}
w(x, y)=\frac{p_{0} a^{4}}{D} \frac{p_{0} \sin \frac{\pi x}{a} \sin \frac{\pi y}{a}}{4 \pi^{4}+\frac{k a^{4}}{D}} ; \\
w_{y y}(a / 2, a / 2)=\frac{p_{0} a^{4}}{D}\left(\frac{\sin ^{2}(\pi / 2)}{4 \pi^{4}+\frac{k a^{4}}{D}}\right) ; \\
w_{\max }=\left(\frac{1}{4 \pi^{4}+\frac{k a^{4}}{D}}\right) \frac{p_{0} a^{4}}{D} .
\end{gathered}
$$

Similarly, the maximum bending and twisting moments for square plates on Winkler foundation for the case of sinusoidal load are:

$$
\begin{aligned}
& M_{x x_{\max }}=\left(\frac{\pi^{2}(1+\mu)}{4 \pi^{4}+\frac{k a^{4}}{D}}\right) p_{0} a^{2}=M_{y y_{\max }} \\
& M_{x y_{\max }}=M_{x y}(x=0, y=0)=\frac{-(1-\mu) \pi^{2} p_{0} a^{2}}{\left(4 \pi^{4}+\frac{k a^{4}}{D}\right)} .
\end{aligned}
$$

\subsection{Ritz variational solution for uniformly distributed load $p(x, y)=p_{0}=$ const}

The Fourier sine series coefficients for the uniformly distributed load are:

$$
p_{m n}=\frac{16 p_{0}}{m n \pi^{2}} .
$$

Then, the Ritz variational solutions become:

$$
\begin{aligned}
& w(x, y)=\frac{16 p_{0}}{\pi^{2} D} \sum_{m}^{\infty} \sum_{n}^{\infty}\left\{\frac{\sin \frac{m \pi x}{a} \sin \frac{n \pi y}{b}}{m n\left[\pi^{4}\left(\left(\frac{m}{a}\right)^{2}+\left(\frac{n}{b}\right)^{2}\right)^{2}+\frac{k}{D}\right]}\right\} \\
& w(a / 2, b / 2)=w_{\max }=\frac{16 p_{0}}{\pi^{2} D} \sum_{m}^{\infty} \sum_{n}^{\infty}\left\{\frac{\sin \frac{m \pi x}{a} \sin \frac{n \pi y}{b}}{m n\left[\pi^{4}\left(\left(\frac{m}{a}\right)^{2}+\left(\frac{n}{b}\right)^{2}\right)^{2}+\frac{k}{D}\right]}\right\}
\end{aligned}
$$

The bending moment distributions are:

$$
\begin{aligned}
& M_{x x}(x, y)=\frac{16 p_{0}}{\pi^{2}} \sum_{m}^{\infty} \sum_{n}^{\infty}\left\{\frac{\left(\left(\frac{m \pi}{a}\right)^{2}+\mu\left(\frac{n \pi}{b}\right)^{2}\right) \sin \frac{m \pi x}{a} \sin \frac{n \pi y}{b}}{m n\left[\left(\left(\frac{m \pi}{a}\right)^{2}+\left(\frac{n \pi}{b}\right)^{2}\right)^{2}+\frac{k}{D}\right]}\right\} \\
& M_{y y}(x, y)=\frac{16 p_{0}}{\pi^{2}} \sum_{m}^{\infty} \sum_{n}^{\infty}\left\{\frac{\left(\left(\frac{n \pi}{b}\right)^{2}+\mu\left(\frac{m \pi}{a}\right)^{2}\right) \sin \frac{m \pi x}{a} \sin \frac{n \pi y}{b}}{m n\left[\left(\left(\frac{m \pi}{a}\right)^{2}+\left(\frac{n \pi}{b}\right)^{2}\right)^{2}+\frac{k}{D}\right]}\right\}
\end{aligned}
$$


The maximum moments occur at the center $(x=a / 2, y=b / 2)$ and are given by:

$$
\begin{aligned}
& M_{x x_{\max }}=16 p_{0} a^{2} \sum_{m}^{\infty} \sum_{n}^{\infty}\left\{\frac{\left(m^{2}+\mu(n r)^{2}\right) \sin \frac{m \pi}{2} \sin \frac{n \pi}{2}}{m n\left[\left(m^{2}+(n r)^{2}\right)^{2} \pi^{4}+\frac{k a^{4}}{D}\right]}\right\} ; \\
& M_{y y_{\max }}=16 p_{0} a^{2} \sum_{m}^{\infty} \sum_{n}^{\infty}\left\{\frac{\left((n r)^{2}+\mu m^{2}\right) \sin \frac{m \pi}{2} \sin \frac{n \pi}{2}}{m n\left[\left(m^{2}+(n r)^{2}\right)^{2} \pi^{4}+\frac{k a^{4}}{D}\right]}\right\}
\end{aligned}
$$

where $r=a / b$.

For square plates $(r=1)$ :

$w_{\max }=\frac{16 p_{0} a^{4}}{D} \sum_{m}^{\infty} \sum_{n}^{\infty}\left\{\frac{\sin \frac{m \pi}{2} \sin \frac{n \pi}{2}}{m n\left[\left(m^{2}+n^{2}\right)^{2} \pi^{4}+\frac{k a^{4}}{D}\right]}\right\}$;

$M_{x x_{\max }}=M_{y y_{\max }}=16 p_{0} a^{2} \sum_{m}^{\infty} \sum_{n}^{\infty} \frac{\left(m^{2}+\mu n^{2}\right) \sin \frac{m \pi}{2} \sin \frac{n \pi}{2}}{m n\left[\left(m^{2}+n^{2}\right)^{2} \pi^{4}+\frac{k a^{4}}{D}\right]}$.

The twisting moments are:

$$
\begin{aligned}
& M_{x y}=-\frac{(1-\mu) 16 p_{0}}{a b} \sum_{m}^{\infty} \sum_{n}^{\infty} \frac{\cos \frac{m \pi x}{a} \cos \frac{n \pi y}{b}}{\left[\pi^{4}\left(\frac{m^{2}}{a^{2}}+\frac{n^{2}}{b^{2}}\right)^{2}+\frac{k}{D}\right]} ; \\
& M_{x y_{\max }}=-\frac{16 p_{0}(1-\mu) a^{3}}{b} \sum_{m}^{\infty} \sum_{n}^{\infty} \frac{1}{\pi^{4}\left(m^{2}+n^{2} r^{2}\right)^{2}+\frac{k a^{4}}{D}} .
\end{aligned}
$$

For square plates:

$$
M_{x y_{\max }}=-16 p_{0}(1-\mu) a^{2} \sum_{m}^{\infty} \sum_{n}^{\infty}\left(\frac{1}{\pi^{4}\left(m^{2}+n^{2}\right)^{2}+\frac{k a^{4}}{D}}\right) \text {. }
$$

\subsection{Ritz variational solutions for linearly distributed load $p(x, y)=p_{0} x / a$}

The Fourier sine series coefficient for linearly distributed load $p(x, y)=p_{0} x / a$ is:

$$
p_{m n}=\frac{8 p_{0} \cos m \pi}{m n \pi^{2}} .
$$

Then the deflection field (function) becomes:

$$
w(x, y)=\frac{8 p_{0} a^{4}}{\pi^{2} D} \sum_{m}^{\infty} \sum_{n}^{\infty} \frac{\cos m \pi \sin \frac{m \pi x}{a} \sin \frac{n \pi y}{b}}{m n\left[\pi^{4}\left(m^{2}+n^{2} r^{2}\right)^{2}+\frac{k a^{4}}{D}\right]} .
$$

At the plate center:

$$
w_{\max }=w(a / 2, b / 2)=\frac{8 p_{0} a^{4}}{\pi^{2} D} \sum_{m}^{\infty} \sum_{n}^{\infty} \frac{\cos m \pi \sin \frac{m \pi}{2} \sin \frac{n \pi}{2}}{m n\left[\pi^{4}\left(m^{2}+n^{2} r^{2}\right)^{2}+\frac{k a^{4}}{D}\right]} .
$$

The bending moments are obtained from the momentdisplacement (moment-curvature) relations as:

$$
\begin{aligned}
& M_{x x}=\frac{8 p_{0} a^{2}}{\pi^{2}} \sum_{m}^{\infty} \sum_{n}^{\infty} \frac{\pi^{2}\left(m^{2}+\mu n^{2} r^{2}\right) \cos m \pi \sin \frac{m \pi x}{a} \sin \frac{n \pi y}{b}}{\left[\pi^{4}\left(m^{2}+(n r)^{2}\right)^{2}+\frac{k a^{4}}{D}\right] m n} ; \\
& M_{y y}=8 p_{0} a^{2} \sum_{m}^{\infty} \sum_{n}^{\infty} \frac{\left(n^{2} r^{2}+\mu m^{2}\right) \cos m \pi \sin \frac{m \pi x}{a} \sin \frac{n \pi y}{b}}{m n\left(\pi^{4}\left(m^{2}+n^{2} r^{2}\right)^{2}+\frac{k a^{4}}{D}\right)} .
\end{aligned}
$$

Bending moments at the plate center, is given by:

$$
\begin{aligned}
& M_{x x}(a / 2, b / 2)=p_{0} a^{2} \cdot 8 \sum_{m}^{\infty} \sum_{n}^{\infty} \frac{\left(m^{2}+\mu(n r)^{2}\right) \cos m \pi \sin \frac{m \pi}{2} \sin \frac{n \pi}{2}}{\left[\pi^{4}\left(m^{2}+(n r)^{2}\right)^{2}+\frac{k a^{4}}{D}\right] m n} \\
& M_{y y_{\max }}=8 p_{0} a^{2} \sum_{m}^{\infty} \sum_{n}^{\infty} \frac{\left(n^{2} r^{2}+\mu m^{2}\right) \cos m \pi \sin \frac{m \pi}{2} \sin \frac{n \pi}{2}}{m n\left(\pi^{4}\left(m^{2}+n^{2} r^{2}\right)^{2}+\frac{k a^{4}}{D}\right)} \cdot
\end{aligned}
$$

For square plates $(r=1)$

$$
\begin{aligned}
& w_{\max }=\frac{8 p_{0} a^{4}}{\pi^{2} D} \sum_{m}^{\infty} \sum_{n}^{\infty} \frac{\cos m \pi \sin \frac{m \pi}{2} \sin \frac{n \pi}{2}}{m n\left(\pi^{4}\left(m^{2}+n^{2}\right)^{2}+\frac{k a^{4}}{D}\right)} ; \\
& M_{x x_{c}}=8 p_{0} a^{2} \sum_{m}^{\infty} \sum_{n}^{\infty} \frac{\left(m^{2}+\mu n^{2}\right) \cos m \pi \sin \frac{m \pi}{2} \sin \frac{n \pi}{2}}{m n\left(\pi^{4}\left(m^{2}+n^{2}\right)^{2}+\frac{k a^{4}}{D}\right)} ;
\end{aligned}
$$

$$
M_{y y_{c}}=8 p_{0} a^{2} \sum_{m}^{\infty} \sum_{n}^{\infty} \frac{\left(n^{2} r^{2}+\mu m^{2}\right) \cos m \pi \sin \frac{m \pi}{2} \sin \frac{n \pi}{2}}{m n\left(\pi^{4}\left(m^{2}+n^{2}\right)^{2}+\frac{k a^{4}}{D}\right)} \text {. }
$$

The Ritz variational solutions for the maximum deflection and maximum bending moments which occur at the plate center $(x=a / 2, y=b / 2)$ for square simply supported Kirchhoff plate resting on Winkler foundation for values

$$
K=\left(\frac{k a^{4}}{D}\right)^{1 / 4}
$$

equal $K=0,1,3$, and 5 have been determined and presented in Table 1 for the case of uniformly distributed transverse load $p_{0}$ over the entire plate domain. Similarly, the Ritz variational solutions for the maximum deflection and maximum bending moments for square simply supported Kirchhoff plates resting on Winkler foundations for values of $K$ equal to $K=0,3,5$ and 7; for the case of sinusoidal load distribution over the plate domain have been determined and are shown in Table 2. 
Table 1 - Ritz variational solution for deflection and bending moment coefficients for simply supported square Kirchhoff plate on Winkler foundation under transverse uniform load (for Poisson's ratio 0.3)

\begin{tabular}{|c|c|c|c|c|c|}
\hline$k a^{4} / D$ & $K$ & $\begin{array}{c}w_{x x}, \\
\times 10^{-3} p a^{4} / D\end{array}$ & $\begin{array}{c}M_{x x}, \\
\times 10^{-2} p a^{2}\end{array}$ & $\begin{array}{c}M_{y y}, \\
\times 10^{-2} p a^{2}\end{array}$ & $\begin{array}{c}M_{x y}, \\
\times 10^{-2} p a^{2}\end{array}$ \\
\hline 0 & 0 & 4.062 & 4.790 & 4.790 & - \\
\hline 1 & 1 & 4.053 & 4.809 & 4.809 & 2.943 \\
\hline 81 & 3 & 3.348 & 3.910 & 3.910 & 2.456 \\
\hline 625 & 5 & 1.507 & 1.575 & 1.575 & 1.181 \\
\hline
\end{tabular}

Table 2 - Ritz variational solutions for maximum deflection and bending moment coefficients for simply supported square Kirchhoff plate on Winkler foundation under transverse sinusoidal load (for Poisson's ratio 0.3)

\begin{tabular}{|c|c|c|c|c|c|}
\hline$k a^{4} / D$ & $K$ & $\begin{array}{c}w_{x x}, \\
\times 10^{-3} p a^{4} / D\end{array}$ & $\begin{array}{c}M_{x x}, \\
\times 10^{-2} p a^{2}\end{array}$ & $\begin{array}{c}M_{y y}, \\
\times 10^{-2} p a^{2}\end{array}$ & $\begin{array}{c}M_{x y}, \\
\times 10^{-2} p a^{2}\end{array}$ \\
\hline 0 & 0 & 2.566 & 3.293 & 3.293 & 1.797 \\
\hline 1 & 1 & 2.560 & 3.285 & 3.285 & 1.792 \\
\hline 81 & 3 & 2.125 & 2.726 & 2.726 & 1.487 \\
\hline 625 & 5 & 0.986 & 1.265 & 1.265 & 0.069 \\
\hline 2401 & 7 & 0.358 & 0.460 & 0.460 & 0.025 \\
\hline
\end{tabular}

\section{Discussion}

The Ritz variational method has been effectively used in this study to solve the flexural problem of simply supported rectangular Kirchhoff plate resting on a Winkler foundation, when the plate domain is subjected to transversely distributed loads. The problem was presented in variational form using the principle of minimization of the total potential energy functional. The total potential energy functional was obtained using the stress-strain laws, the geometric relations in the strain energy density expression together with the considerations of work done by the externally applied distributed loads, and soil reactive forces. The total energy functional for the problem was obtained as Equation (28). The variational statement of the problem was then expressed as Equation (29). The displacement shape functions that satisfy the simply supported conditions at the plate edges were given as Equations (38) and (39). The Ritz variational solution obtained for any arbitrary distribution of transverse load was given as Equaton (52) where the arbitrary load distribution could be described using Fourier sine series. The bending and twisting moments were found using the moment curvature relations as Equations (57), (58) and (59). From the general solutions obtained for arbitrary load distributions, solutions were obtained for the following specific cases:

1) point load $P_{0}$ acting at a point $\left(x_{0}, y_{0}\right)$ in the plate domain where $0 \leq x_{0} \leq a, 0 \leq y_{0} \leq b$; face;

2) sinusoidal load distribution over the entire plate sur-

3) uniform load distribution over the entire plate area;

4) hydrostatic (linear) distribution of load over the entire plate.
Ritz variational solutions obtained for the deflections and bending moments for the case of point load $P_{0}$ acting at point $\left(x_{0}, y_{0}\right)$ on the plate are given as equations (23). Their maximum values for square thin plates on Winkler foundations were obtained as equations (24) and (25).

For the case of transverse sinusoidal load, the deflections and bending moments were obtained as equations (26). Their maximum values for square Kirchhoff plates on Winkler foundations were found at the plate center as equations (27), (28) and (29).

The Ritz variational solution for the case of uniformly distributed transverse load were found for deflection and bending moments as equations (31) and (32). The maximum values for deflection and bending moments for square Kirchhoff plate on Winkler foundation were found as equations (31), (33) and (34).

The Ritz variational solutions for linearly distributed transverse load on the Kirchhoff plate on Winkler foundation were obtained as equations (38) and (40). The deflections and bending moments were obtained at the plate center as equations (39) and (41). For square Kirchhoff plate on Winkler foundation, the solutions for linear loads are Equations (42). Here the maximum values may not occur at the plate center due to the non-symmetrical load distribution with respect to the plate center.

The Ritz variational solutions obtained for square Kirchhoff plate on Winkler foundation for the case of uniform transverse load and simply supported edges shown tabulated in Table 1 for various values of the dimensionless parameter $K$ show that the maximum deflections and bending and twisting moments at the plate center decrease as the elastic stiffness of the Winkler foundation, measured by parameter $K$ increases. It is further observed that the Ritz variational solutions obtained in this study for Kirchhoff plate on Winkler foundation with simply supported edges ( $x=0, x=a, y=0, y=b)$ yielded mathematical closed form solutions which were identical with the solutions obtained using a Navier double Fourier sine series method for the problem.

\section{Conclusions}

As a result of the presented research, the following conclusions are made.

The Ritz variational method yielded mathematically closed form solutions for the deflection, and bending moments for the rectangular Kirchhoff plate on Winkler foundation with simply supported edges, and under transverse distributed load.

The analytical closed form solutions obtained were exact within the limitations and foundational assumptions of the classical Kirchhoff thin plate theory and the Winkler foundation model used in the problem formulation.

The Ritz variational solutions were exactly identical with the solutions obtained using Navier trigonometric series method for the same problem.

The Ritz variational solutions obtained were exact because exact shape functions were used in the displacement trial function. 
The Winkler foundation has the effect of diminishing the maximum deflections and bending moments at the center of the plate for symmetrical loads about the plate center.

The use of displacement functions with orthogonality properties simplified the resulting definite integrations and simplified the process of minimization of the total potential energy functional.
Convergence of the expressions obtained for the displacements were faster than those obtained for the bending moments.

Convergence of the expressions obtained for the case of concentrated load on the plate was very slow due to the singularity property of the point load, and its representation by many terms of the Fourier sine series.

\section{References}

1. Reissner, E. (1944). On the theory of bending of elastic plates. Journal of Mathematics and Physics, Vol. 23, pp 184-191.

2. Reissner, E. (1945). The effect of shear deformation on the bending of elastic plates. Journal of Applied Mechanics, Vol. 12, pp 69-75.

3. Mindlin, R. D. (1951). Influence of rotary inertia on flexural motion of isotropic, elastic plates. Journal of Applied Mechanics, Vol 18(1), pp. 31-38.

4. Shimpi, R. P. (2002). Refined plate theory and its variants. AIAA Journal, Vol. 40, pp 137-146.

5. Reddy, J. N. (1984). A refined non linear theory of plates with transverse shear deformation. International Journal of Solids and Structures, Vol. 20, pp. 881-896.

6. Mama, B. O., Ike, C. C., Onah, H. N., \& Nwoji, C. U. (2017) Analysis of rectangular Kirchhoff plate on Winkler foundation using finite Fourier sine transform method. IOSR Journal of Mathematics, Vol. 13(1), pp 58-66, doi: 10.9790/5728-1301065866.

7. Caselunghe, A., \& Eriksson, J. (2012). Structural Element Approaches for Soil Structure Interaction. MSc thesis, Chalmer University of Technology, Goteborg, Sweden.

8. Rajpurohit, V. K., Gore, N. G., \& Sayagavi, V. G. (2014). Analysis of structures supported on elastic foundations. International Journal of Engineering and Technology, Vol. 4(1), pp. 1-6.

9. Ghaitani, M. M., Esmaieili, H. A., \& Kolahchi, R. (2014). Elastic foundation effect on bending behavior of oil pipelines. International Conference on Civil, Biological and Environmental Engineering, Istanbul, Turkey, pp. 36-39.

10. Winkler, E. (1867). Lehre vouder elastizitat und festigkeit. Dominicus, Prague.

11. Pasternak, P. L. (1954). On a new method of analysis of an elastic foundation by means of two foundation constants. State Publishing House, Moscow [in Russian].

12. Filonenko-Borodich, M. M. (1945). A very simple model of an elastic foundation capable of spreading the load. Proceeding of the Moscow Electronic Institure, Moscow, Russia.

13. Hetenyi, M. (1946). Beams on Elastic Foundation: Theory with Applications in the fields of Civil and Mechanical Engineering. The University of Michigan Press, Ann Arbor, Michigan.

14. Kerr, A. D (1964). Elastic and visco-elastic foundation models. Journal of Applied Mechanics, Vol. 31, pp. 491-498.

15. Ike, C. C. (2017). Flexural analysis of Kirchhoff plates on Winkler foundations using finite Fourier sine integral transform method. Mathematical Modelling of Engineering Problems, Vol. 4(4), pp. 145-154, doi: 10.18280/mmep.040402.

16. Althobaiti S, Prikazchikov D.A. (2016). Edge bending waves on an orthotropic elastic plate resting on the Winkler-Fuss foundation. Vol. 69(1), pp. 16-24.

17. Zhong, Y., Zhao, X.-F., \& Hu, H. (2014). Vibration of plate on foundation with four edges free by finite cosine integral transform method. Latin American Journal of Solids and Structures, Vol. 11(5), pp. 854-863.

18. Li, R., Zhong, Y., \& Li, M. L. (2013). Analytic bending solutions of free rectangular thin plates resting on elastic foundations by a new symplectic superposition method. Proceedings of the Royal Society, Vol. 46, pp. 468-474.

19. Li, R., Zhong, Y., \& Tian, B. (2011). On new symplectic superposition method for exact bending solutions of rectangular cantilever thin plates. Mechanics Research Communications, Vol. 38, pp 111-116.

20. Li, R., Zhong, Y., Tian, B., \& Lin, Y. M. (2009). On the finite integral transform method for exact bending solutions of fully clamped orthotropic rectangular thin plates. Applied Mathematics Letters, Vol. 22(12), pp. 1821-1827.

21. Zhang, H., Shi, O. H., \& Wang, Q. S. (2016). Free vibration analysis of the moderately thick laminated composite rectangular plate on two-parameter elastic foundation with elastic boundary conditions. ASRTU Symposium on Advanced Materials and Processing Technology, Vol. 2016, pp. 189-192, doi: 10.18502/kms.vi/1.584.

22. Agarana, M. C., Gbadeyan, J. A., \& Ajayi, O. O. (2016). Dynamic response of inclined isotropic elastic clamped rectangular Mindlin plate resting on Pasternak foundation under a moving load. Proceedings of the International Multiconference of Engineers and Computer Scientists, IMECS 2016, Vol II, pp. 1-6.

23. Are E.B., Idowu A.S, Gbadeyin J.A (2013). Vibrations of damped simply supported orthotropic plate resting on elastic Winkler's foundation subjected to moving loads. Advances in Applied Science Research Vol 4, No 5, pp. 387 - 393.

24. Agarana, M. C., \& Gbadeyan, J. A. (2015). Finite difference dynamic analysis of railway bridges supported by Pasternak foundation under uniform partially distributed moving railway vehicle. International Conference on Systems Engineering and Engineering Management, WCECS 2015, Vol. II, pp. 1-5. 
25. Tahouneh, V., \& Yas, M. H. (2012). 3D free vibration analysis of thick functionally graded annular sector plates on Pasternak foundation via 2-D differential quadrature method. Acta Mechanica, Vol. 223(9), pp. 1879-1897.

26. Ye, T., Jin, G., Su, Z., \& Chen, Y. (2014). A modified Fourier solution for vibration analysis of moderately thick laminated plate with general boundary restraints. International Journal of Mechanical Sciences, Vol. 80, pp 29-46.

\title{
Застосування варіаційного методу Рітца для дослідження вигину прямокутної пластини на вінклеровій основі
}

\author{
Іке Ч. Ч.
}

Державний університет науки і технології м. Енугу, П.М.Б. 01660, м. Енугу, Нігерія

\begin{abstract}
Анотація. У роботі застосовано варіаційний метод Рітца до роз'язання задачі вигину прямокутної пластини на вінклеровій основі під дією поперечного навантаження за умов відповідності гіпотезам Кірхгофа для випадку шарнірно закріплених країв. Поставлена задача представлена у варіаційній формі із застосуванням принципу мінімуму функціонала повної потенціальної енергії пластини. Для отримання узагальнених переміщення застосовано метод Рітца для функцій переміщення, що задовольняють кінематичні граничні умови задачі. Шляхом застосування тригонометричного ряду Фур'є отримані аналітичні розв'язки для загального випадку довільно розподіленого навантаження. Додатково розглянуто окремі випадки, зокрема, для прикладення сили у точці, навантаження за синусоїдальним законом розподілу, а також для рівномірного та рівнозмінного навантажень.
\end{abstract}

Ключові слова: варіаційний метод Рітца, гіпотеза Кірхгофа, вінклерова основа, функціонал повної потенціальної енергії, узагальнені переміщення, базисні функції переміщення. 